\title{
Identification and Antimicrobial Susceptibility Pattern of Clinically Significant Coagulase-negative Staphylococci
}

\author{
Nazir A ${ }^{1}$, Shah $\mathbf{A}^{2}$, Kakru $\mathbf{D}^{3}$, Kadri SM${ }^{4}$ \\ ${ }^{1}$ Department of Microbiology, Government Medical College, Srinagar, ${ }^{2}$ Department of Pathology and Microbiology, \\ SKIMS, Srinagar, ${ }^{3}$ Department of Microbiology, SKIMS, Srinagar, ${ }^{4}$ Directorate of Health Services, Srinagar, Kashmir, \\ India
}

Received: June 7, 2013; Accepted: December 9, 2014

\begin{abstract}
Aims: This study was undertaken to determine the prevalence and pathogenicity of coagulase-negative staphylococci in clinical samples and to study the antibiotic-sensitivity pattern of the coagulase-negative isolates.

Methods: A prospective study was conducted over a period of two years on patients admitted in the Sher-i-Kashmir Institute of Medical Sciences. Blood, urine, pus, catheter tips, cerebrospinal fluid and peritoneal fluid samples of patients who fulfilled the criteria for being labeled as nosocomial were cultured.

Results: One hundred and six strains of coagulase negative staphylococci were isolated from the samples and among them 90 isolates were identified as Staphylococcus epidermidis (84.90\%). Most of the coagulase-negative staphylococci isolates were resistant to penicillin, cephalosporins and fluoroquinolones. Methicillin resistance was found in a significant number of coagulase-negative isolates. All the isolates were found to be sensitive to vancomycin.
\end{abstract}

Conclusions: The results of the study emphasized that isolation of coagulase-negative staphylococci should be viewed with serious concern and accurate species identification and antimicrobial susceptibility testing should be performed in all cases.

Keywords: antimicrobial susceptibility testing; coagulase-negative staphylococci (ConS); nosocomial pathogens.

\section{INTRODUCTION}

Coagulase-negative staphylococci (ConS) are commensals commonly found on human skin and mucous membranes. They have the potential to cause serious human disease due to their ability to become pathogenic when alterations in the integument allow them to enter into the body. ConS had long been regarded as harmless skin commensals and dismissed as culture contaminants. ${ }^{1-3}$ Their role as pathogens was increasingly suspected and studied and they are now regarded as well established agents of infection. The resistance of these organisms to a wide-range of antimicrobial agents is well documented. The increasing incidence of infections by these bacteria can be attributed to their affinity for the foreign materials that are integral to modern medicine. ${ }^{4}$ The increasing use of prosthetic devices, intravascular catheters, and other invasive technologies in patients who are sick, more immunosuppressed, and at the extremes of life has brought ConS to the forefront of

\section{CORRESPONDENCE}

Dr Asifa Nazir

Department of Microbiology, Government Medical College, Srinagar, India

Email: asifanazir@gmail.com

Phone: +91-9419004608 nosocomial pathogens. The isolation of ConS should be viewed with serious concern and accurate species identification and antimicrobial susceptibility testing should be performed in all cases. Also the increasing significance of ConS as one of the leading nosocomial pathogens needs to be recognized.

\section{METHODS}

This study was conducted in the Department of Microbiology at Sher-i-Kashmir Institute of Medical Sciences, Soura, India, from June 2001 to June 2003. The institutional review board approved the study protocol, informed consent document and procedures. Patients who fulfilled the criteria for being labeled as nosocomial (i.e. who developed an infection after 48 hours of hospital admission) were included in the study.

Blood samples were collected from patients with septicemia, patients with central venous catheter, peripheral intravenous and other catheters, patients from surgical, medical and neonatal intensive care units, immunocompromised patients and patients with 
prosthetic valve endocarditis. Intravascular catheter segments, catheter tips or central venous catheter hubs were collected from patients on intravenous or other catheters. Aspirates were collected from joint spaces in patients with prosthetic implants and CSF from patients with ventriculoperitoneal shunt and patients with epidural catheter. Peritoneal fluid was taken from patients with chronic ambulatory peritoneal dialysis (CAPD) and pus from patients with surgical site infections and diabetic patients with ulcers or abscesses. Urine samples were collected from patients with indwelling urinary catheters and young sexually active females with recurrent urinary tract infections and vascular graft material or swab were also collected.

Clinical samples were processed on blood agar, MacConkey agar, nutrient agar, mannitol salt agar and cooked meat broth. Each specimen was plated on blood agar and other media as indicated under all aseptic conditions and incubated at $37^{\circ} \mathrm{C}$ for 24 hours and subsequently for 48 hours. In addition culture of intravenous catheter segment was performed according to the semi-quantitative method of Maki et al..$^{5}$ Catheter segments were cultured after rolling over a blood agar plate and incubated for 18 hours at $37^{\circ} \mathrm{C}$ after which the number of colony forming units (cfu) was counted. Cultures yielding more than $15 \mathrm{cfu}$ were associated with catheter-related bacteremia.

The coagulase- negative staphylococci were identified by the colony appearance on blood agar, nutrient agar and MacConkey agar. On mannitol salt agar, ConS formed small orange colonies surrounded by red or purple medium. Gram staining was done followed by catalase test. Slide coagulase test was done to detect the bound coagulase or clumping factor. Tube coagulase test was done to confirm the findings of the slide coagulase test. Once an organism was confirmed as ConS, it was further characterized by the scheme recommended by the sub-committee on the taxonomy of Staphylococci and Micrococcus. Antimicrobial sensitivity of ConS was done by Stokes disc diffusion method. Minimum inhibitory concentration (MIC) was determined by broth dilution method. Control strain used for performing MIC was Staphylococcus ATCC 29213.

\section{RESULTS}

Out of a total of 3100 nosocomial infections studied, 106 cases were due to coagulase- negative staphylococci infections, with a prevalence of $3.42 \%$. Table 1 shows the distribution of the 106 isolates from various sources.

Table 1. Distribution of $\mathbf{1 0 6}$ isolates of coagulase negative staphylococci from various sources $(n=106)$.

\begin{tabular}{|ll|}
\hline Specimen & Number (\%) \\
\hline Blood & $34(32.07)$ \\
Urine & $26(24.53)$ \\
$\begin{array}{l}\text { Catheter tips/drain } \\
\text { tips/ IV cannulas }\end{array}$ & $14(13.21)$ \\
Pus & $12(11.33)$ \\
Cerebro-spinal & $10(9.43)$ \\
fluids & $10(9.43)$ \\
Peritoneal fluid & 10 \\
\hline
\end{tabular}

There was a significant difference in prevalence of various clinical groups $(\mathrm{p}$ value $=0.0342)$._The incidence of infection was higher in males $(65 \%)$ than in females (35\%). The association between ConS infection and sex was statistically significant.

Most of the isolates were from catheterized patients, patients with intravascular prosthetic devices, patients in intensive care units and postoperative wards. The prevalence was $3.77 \%$ in nosocomial bacteremias, $3.25 \%$ in nosocomial urinary tract infections, $2 \%$ in wound infections, $2.50 \%$ in meningitis and $5.00 \%$ in peritonitis (Table 2).

Table 2. Prevalence of coagulase-negative staphylococci infections in clinical samples collected from various sources in department of microbiology, SKIMS, Soura.

\begin{tabular}{|llccl|}
\hline Infection & Specimen & Cases & $\begin{array}{l}\text { Cons } \\
\text { isolates }\end{array}$ & $\begin{array}{l}\text { Rate } \\
\mathbf{( \% )}\end{array}$ \\
\hline $\begin{array}{l}\text { Bacteremia } \\
\begin{array}{l}\text { Urinary tract } \\
\text { infections }\end{array}\end{array}$ & Blood & 900 & 34 & 3.77 \\
$\begin{array}{l}\text { Wound } \\
\text { infections }\end{array}$ & Pus & 800 & 26 & 3.25 \\
$\begin{array}{l}\text { Meningitis } \\
\text { Peritonitis }\end{array}$ & CSF & 600 & 12 & 2.00 \\
$\begin{array}{l}\text { On i.v } \\
\text { lines/in- } \\
\text { dwelling } \\
\text { devices }\end{array}$ & $\begin{array}{l}\text { i.v tips/ } \\
\text { drain tips }\end{array}$ & 200 & 14 & 7.00 \\
\hline
\end{tabular}

Ninety out of the 106 isolates were identified as Staphylococcus epidermidis $(84.90 \%)$ and 16 as 
Staphylococcus saprophyticus (15.09\%).

There was an association of ConS with underlying clinical disorders. $43 \%$ of bacteremias due to ConS were associated with the use of central venous catheters and prosthetic devices, $22 \%$ of the isolates were from patients with underlying leukemia or lymphoma, $20 \%$ from patients admitted to neonatal intensive care unit and $8 \%$ patients either had diabetes or chronic renal failure. $60 \%$ of isolates recovered from peritoneal fluid were obtained from patients on chronic ambulatory dialysis.

Tables 3 and 4 show the antibiotic sensitivity and resistance pattern of ConS strains isolated from various clinical samples. The most effective antibiotic agents used against the 106 coagulase-negative staphylococci were vancomycin (100\%) and methicillin (83.96\%) followed by amikacin $(70 \%)$, gentamycin $(66.1 \%)$, norfloxacin $(64.15 \%)$ and ciprofloxacin $(61.3 \%)$ cefotaxime $(58.49 \%)$ and cephalexin $(57.5 \%)$.

Table 3. Antibiotic sensitivity and resistance pattern of coagulase-negative isolates.

\begin{tabular}{|lccl|}
\hline Antimicrobial Agent & $\begin{array}{l}\text { Antibiotic content } \\
\text { in disc }(\boldsymbol{\mu g})\end{array}$ & $\begin{array}{l}\text { No. of sensitive strains } \\
(\mathbf{\%})\end{array}$ & $\begin{array}{l}\text { No. of resistant strains } \\
(\%)\end{array}$ \\
\hline Penicillin-P & $10 \mu \mathrm{g}$ & $10(9.4 \%)$ & $96(90.1 \%)$ \\
Amoxycillin-A & $30 \mu \mathrm{g}$ & $16(15.1 \%)$ & $90(84.9 \%)$ \\
Gentamycin-G & $10 \mu \mathrm{g}$ & $70(66.1 \%)$ & $36(33.96 \%)$ \\
Amikacin-Ak & $30 \mu \mathrm{g}$ & $74(70 \%)$ & $32(30.18 \%)$ \\
Ciprofloxacin-C & $5 \mu \mathrm{g}$ & $65(61.3 \%)$ & $41(38.67 \%)$ \\
Cephalexin-Cp & $30 \mu \mathrm{g}$ & $61(57.5 \%)$ & $45(42.45 \%)$ \\
Cefotaxime-Ce & $30 \mu \mathrm{g}$ & $62(58.49 \%)$ & $44(41.5 \%)$ \\
Norfloxacin-Nf & $10 \mu \mathrm{g}$ & $68(64.15 \%)$ & $38(35.84 \%)$ \\
Methicillin-M & $5 \mu \mathrm{g}$ & $89(83.96 \%)$ & $17(16.03 \%)$ \\
Vancomycin-V & $30 \mu \mathrm{g}$ & $106(100 \%)$ & - \\
\hline
\end{tabular}

Table 4. Distribution of resistance pattern of 106 coagulase-negative isolates from various clinical samples.

\begin{tabular}{|c|c|c|c|c|c|c|c|c|c|c|c|c|}
\hline$\underbrace{\infty}_{0}$ & 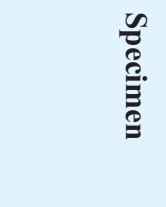 & 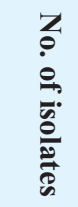 & 总. & 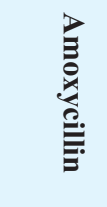 & 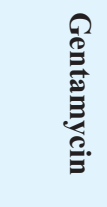 & $\begin{array}{l}\text { D. } \\
\text { E. } \\
\text { 茯. } \\
\text { 量. }\end{array}$ & 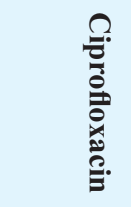 & 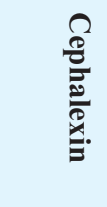 & 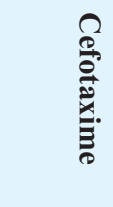 & 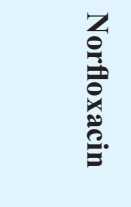 & & 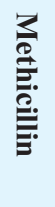 \\
\hline 1. & Blood & 34 & $\begin{array}{l}31 \\
(91.1)\end{array}$ & $\begin{array}{l}29 \\
(85.2)\end{array}$ & $\begin{array}{l}9 \\
(26.4)\end{array}$ & $\begin{array}{l}8 \\
(23.5)\end{array}$ & $\begin{array}{l}10 \\
(29.4)\end{array}$ & $\begin{array}{l}12 \\
(35.2)\end{array}$ & $\begin{array}{l}11 \\
(32.3)\end{array}$ & $\begin{array}{l}10 \\
(29.4)\end{array}$ & $\begin{array}{l}3 \\
(8.8)\end{array}$ & \\
\hline 2. & Urine & 26 & $\begin{array}{l}24 \\
(92.3)\end{array}$ & $\begin{array}{l}23 \\
(88.4)\end{array}$ & $\begin{array}{l}4 \\
(15.3)\end{array}$ & $\begin{array}{l}3 \\
(11.5)\end{array}$ & $5(19.2)$ & $\begin{array}{l}6 \\
(23.0)\end{array}$ & $\begin{array}{l}7 \\
(26.9)\end{array}$ & $5(19.2)$ & $\begin{array}{l}3 \\
(11.5)\end{array}$ & \\
\hline 3. & $\begin{array}{l}\text { Catheter } \\
\text { tips etc. }\end{array}$ & 14 & $\begin{array}{l}12 \\
(85.7)\end{array}$ & $\begin{array}{l}10 \\
(71.4)\end{array}$ & $\begin{array}{l}5 \\
(35.7)\end{array}$ & $\begin{array}{l}5 \\
(35.7)\end{array}$ & $6(42.8)$ & $\begin{array}{l}7 \\
(50)\end{array}$ & $\begin{array}{l}6 \\
(42.8)\end{array}$ & $\begin{array}{l}5 \\
(35.7)\end{array}$ & $\begin{array}{l}2 \\
(14.2)\end{array}$ & \\
\hline 4. & Pus & 12 & $\begin{array}{l}11 \\
(91.6)\end{array}$ & $\begin{array}{l}10 \\
(83.3)\end{array}$ & $\begin{array}{l}5 \\
(41.6)\end{array}$ & $\begin{array}{l}4 \\
(33.3)\end{array}$ & $\begin{array}{l}6 \\
(50)\end{array}$ & $\begin{array}{l}7 \\
(58.3)\end{array}$ & $\begin{array}{l}8 \\
(66.6)\end{array}$ & $8(66.6)$ & $\begin{array}{l}4 \\
(33.3)\end{array}$ & \\
\hline 5. & $\mathrm{CSF}$ & 10 & $\begin{array}{l}9 \\
(90)\end{array}$ & $\begin{array}{l}8 \\
(80)\end{array}$ & $\begin{array}{l}5 \\
(50)\end{array}$ & $\begin{array}{l}5 \\
(50)\end{array}$ & $\begin{array}{l}7 \\
(70)\end{array}$ & $\begin{array}{l}8 \\
(80)\end{array}$ & $\begin{array}{l}7 \\
(70)\end{array}$ & $\begin{array}{l}5 \\
(50)\end{array}$ & $\begin{array}{l}3 \\
(30)\end{array}$ & \\
\hline \multirow[t]{3}{*}{6.} & $\begin{array}{l}\text { Peritoneal } \\
\text { Fluid }\end{array}$ & 10 & $\begin{array}{l}9 \\
(90)\end{array}$ & $\begin{array}{l}10 \\
(100)\end{array}$ & $\begin{array}{l}8 \\
(80)\end{array}$ & $\begin{array}{l}7 \\
(70)\end{array}$ & $\begin{array}{l}7 \\
(70)\end{array}$ & $\begin{array}{l}5 \\
(50)\end{array}$ & $\begin{array}{l}5 \\
(50)\end{array}$ & $\begin{array}{l}5 \\
(50)\end{array}$ & $\begin{array}{l}2 \\
(20)\end{array}$ & \\
\hline & Total & 106 & 96 & 90 & 36 & 32 & 41 & 45 & 44 & 38 & 17 & \\
\hline & Percentage & & $(90.1)$ & $(84.9)$ & $(33.9)$ & $(30.1)$ & $(38.6)$ & (42.4) & $(41.5)$ & $(35.8)$ & $(16.0)$ & \\
\hline
\end{tabular}

Note: Figures in parentheses show percentages 
The least sensitive antimicrobial agents were penicillin (9.4\%) and amoxycillin (15.1\%). Among the ConS isolates from blood $91.7 \%$ were resistant to penicillin and $85.29 \%$ were resistant to amoxycillin. Similarly $35.29 \%, 32.35 \%, 29.4 \%, 29.4 \%$, 26.24\%, $23.5 \%$ and $8.82 \%$ were resistant to cephalexin, cefotaxime, norfloxacin, ciprofloxacin, gentamycin, amikacin and methicillin respectively. Among the ConS isolated from urine, $92.5 \%$ were resistant to penicillin and similarly $88.46 \%, 26.92 \%, 23.07 \%$, $19.23 \%, 19.23 \%, 15.38 \%, 11.53 \%, 11.53 \%, 23.5 \%$ and $8.82 \%$ were resistant to amoxycillin, cefotaxime, cephalexin, ciprofloxacin norfloxacin, gentamycin, amikacin and methicillin, respectively. In those isolated from catheter tips, $85.7 \%$ strains of were resistant to penicillin and similarly $71.42 \%, 50 \%$, $42.85 \%, 42.85 \%, 35.71 \%, 35.71 \%, 35.71 \%$ and $14.28 \%$ were resistant to amoxycillin, cephalexin, cefotaxime, ciprofloxacin, amikacin, gentamycin, norfloxacin and methicillin respectively. Among the strains isolated from pus samples, $91.66 \%$ were resistant to penicillin and similarly $83.33 \%, 66.6 \%$, $66.6 \%, 58.33 \%, 50 \%, 41.66 \%, 33.33 \%$, and $33.33 \%$ were resistant to amoxycillin, cefotaxime, norfloxacin, cephalexin, ciprofloxacin, gentamycin, amikacin, and methicillin, respectively. In the strains isolated from cerebrospinal fluid $90 \%$ were resistant to penicillin and similarly $80 \%, 80 \%, 70 \%, 70 \%, 50 \%, 50 \%, 50 \%$ and $30 \%$ were resistant to amoxycillin, cephalexin, cefotaxime, ciprofloxacin, norfloxacin, gentamycin, amikacin, and methicillin, respectively. Hundred percent of strains of the ConS isolated from peritoneal fluid were resistant to amoxycillin and similarly $90 \%, 80 \%, 70 \%, 70 \%, 50 \%, 50 \%, 50 \%$ and $20 \%$ were resistant to penicillin, gentamycin, amikacin, ciprofloxacin, cephalexin, cefotaxime, norfloxacin, and methicillin, respectively.

\section{DISCUSSION}

Coagulase-negative staphylococci, which were earlier dismissed as contaminants, have now emerged as important potential pathogens. They have become increasingly resistant to antibiotics- the most recent threat being the emergence of strains with moderate levels of resistance to vancomycin. ${ }^{6}$

In the present study, the prevalence of ConS infection in Sher-i-Kashmir Institute of Medical Sciences was $3.42 \%$. The prevalence was $3.77 \%$ in nosocomial bacteremias, $3.25 \%$ in nosocomial urinary tract infections, $2 \%$ in wound infections, $2.50 \%$ in meningitis and $5.00 \%$ in peritonitis. Sidebottom et $\mathrm{al}^{7}$ in 1988 also noted a prevalence of $4.4 \%$ during their 15 -years study on the blood stream isolates of ConS in neonatal intensive care patients. Edgeworth et $\mathrm{al}^{8}$ reported a prevalence of $3.7 \%$ in patients of bacteremia. Ninety out of the 106 isolates were identified as Staphylococcus epidermidis (84.90\%) and 16 as Staphylococcus saprophyticus (15.09\%). Akatov et $\mathrm{al}^{9}$ in 1981 isolated $55.1 \%$ S. epidermidis species and $13.5 \%$ S. saprophyticus species in their study of ConS isolates from clinical specimens.

The results of earlier studies ${ }^{10-12}$ conducted on blood samples are consistent with our study with rates of isolation ranging from $33.7 \%$ to $51.1 \%$. Our results are also in accordance with those of Pal and Ayyagari ${ }^{13}$ who found that the most common source of ConS from various clinical specimens was blood (37.35\%), followed by urine $(22.6 \%)$ and cerebrospinal fluid (20\%). In our study, 43\% of bacteremias due to ConS were associated with the use of central venous catheters and prosthetic devices, $22 \%$ of the isolates were from the patients with underlying leukemia or lymphoma, $20 \%$ from the patients admitted to neonatal intensive care unit and $8 \%$ patients either had diabetes or chronic renal failure. These results are in accordance with the findings of other studies. ${ }^{14-16}$ Also, according to Smith et $\mathrm{al}^{17} 69 \%$ of the infections due to ConS were associated with the use of prosthetic devices. Stillman et $\mathrm{al}^{18}$ reported increased rates of coagulase-negative staphylococcal blood stream infections and $64 \%$ of these were found in critical care areas. The EPIC ${ }^{19}$ study in Europe gave a prevalence rate of $44.9 \%$ in intensive care units, which was associated with the increasing use of intravascular catheters.

An important aspect of the emergence of coagulasenegative infections is the development of resistance to antimicrobial agents. The most effective antibiotic agents used against the $106 \mathrm{ConS}$ were vancomycin $(100 \%)$ and methicillin $(83.96 \%)$ followed by amikacin $(70 \%)$, gentamycin $(66.1 \%)$, norfloxacin $(64.15 \%)$ and ciprofloxacin $(61.3 \%)$ cefotaxime (58.49\%) and cephalexin (57.5\%). The least sensitive antimicrobial agents were penicillin (9.4\%) and amoxicillin (15.1\%). 
These results are consistent with those of Richardson et $\mathrm{al}^{20}$ who concluded that $80-85 \%$ of clinically significant ConS isolated in their study were resistant to penicillin and more than $30 \%$ were resistant to methicillin. Refsahl and Anderson ${ }^{14}$ in 1992, noted methicillin resistance in $30.5 \%$ of the ConS. Our findings are similar to other studies ${ }^{2,3}$ conducted in India. Pal and Ayyagari ${ }^{13}$ stated that $14.6 \%$ of their ConS isolates were resistant to methicillin while vancomycin was effective against all the isolates. Also Deepak et al ${ }^{21}$ showed more than $80 \%$ of their ConS isolates were resistant to penicillin, $75 \%$ to ampicillin and $79 \%$ to trimethoprim.

MIC was determined for multi-drug resistant strains. MIC for penicillin, amoxycillin and amikacin was 64$256 \mu \mathrm{g} / \mathrm{ml}$, for gentamycin 32-128 $\mu \mathrm{g} / \mathrm{ml}, 32-256 \mu \mathrm{g} /$ $\mathrm{ml}$ for cephalexin and cefotaxime, $16-128 \mu \mathrm{g} / \mathrm{ml}$ for ciprofloxacin, 16-64 $\mu \mathrm{g} / \mathrm{ml}$ for norfloxacin and MIC for methicillin was $16-32 \mu \mathrm{g} / \mathrm{ml}$. Ponce de et $\mathrm{al}^{22}$ found MIC of more than $64 \mu \mathrm{g} / \mathrm{ml}$ for multi-drug resistant strains of ConS for penicillin, methicillin, cefotaxime, amikacin, gentamycin, rifampicin and vancomycin while rest of the strains had an intermediate resistance with MIC's of 16-32 $\mu \mathrm{g} / \mathrm{ml}$.

Richardson et $\mathrm{al}^{20}$ noted that the MIC of the various ConS isolates was more than $256 \mu \mathrm{g} / \mathrm{ml}$ for gentamycin, tobramycin and kanamycin. Also, Foleno et al, ${ }^{23}$ during their study of ConS found that the MIC for ciprofloxacin, norfloxacin and enoxacin was between $64-128 \mu \mathrm{g} / \mathrm{ml}$.

\section{CONCLUSIONS}

Coagulase-negative staphylococci are currently among the most common cause of infections in hospitalized patients. Increasing resistance to antibiotics would indicate that their prevalence will continue to rise. Although the incidence of methicillin-resistant Staphylococcus epidermidis strains and other methicillin resistant staphylococci varies from hospital to hospital, a steady increase has been observed and often exceeds 50\%. Coagulasenegative methicillin-resistant staphylococci are a major cause of medical device-associated infections, especially in immunocompromised patients, and the excessive use of vancomycin in the empirical treatment is complicated by the emergence of multidrug resistant strains. The results of the present study emphasize that isolation of ConS should be viewed with serious concern and accurate species identification and antimicrobial susceptibility testing should be performed in all cases.

\section{DISCLOSURE}

The authors report no conflicts of interest in this work.

No violation of human rights and safety.

Funding: Nil

\section{REFERENCES}

1. Dandalides PC, Rutala WA, Thomann CA, Sarubbi FA. Serious postoperative infections caused by coagulasenegative staphylococci: an epidemiological and clinical study. J Hosp Infect. 1986;8:233-41.

2. Seetha KS, Santosh PK, Shivananda PG. Study of coagulasenegative staphylococci isolated from blood and CSF cultures Indian J Pathol Microbiol. 2000;43:41-5.

3. Mohan U, Jindal N, Aggarwal P. Species distribution and antibiotic sensitivity pattern of coagulase negative staphylococci isolated from various clinical specimens. Indian J Med Microbiol. 2002;20:45-6.

4. O'Gara JP, Humphreys H. Staphylococcus epidermidis biofilms importance and implications. J Med Microbiol. 2001;50:582-7.

5. Maki DG, Weise CE, Sarafin HW. A semiquantitative culture method for identifying intravenous-catheter-related infection. N Engl J Med. 1977;296:1305-9.
6. Huebner J, Goldmann DA. Coagulase-negative staphylococci: role as pathogens. Annul Rev Med. 1999;50:223-6.

7. Sidebottom DG, Freeman J, Platt R, Epstein MF, Goldmann DA. Fifteen-year experience with bloodstream isolates of coagulase-negative staphylococci in neonatal intensive care. J Clin Microbiol. 1988;26:713-8.

8. Edgeworth JD, Treacher DF, Eykyn SJ.A 25- year old study of nosocomial bacteremia in an adult intensive care unit. Crit Care Med. 1999;27:1421-8.

9. Akatov AK, Khatenever ML. Coagulase-negative staphylococci isolated from patients II. Species diversity of strains. Zh Mikrobiol Epidemiol Immunobiol. 1981;3:45-50.

10. Ponce de Leon S, Guenthner SH, Wenzel RP. Microbiologic studies of coagulase-negative staphylococci isolated from patients with nosocomial bacteremias. J Hosp Infect. 1986;7:121-9. 
11. Souvenir D, Anderson DE Jr., Palpant S, Mroch H, Askin $\mathrm{S}$, Anderson J. et al. Blood cultures positive for coagulasenegative staphylococci: antisepsis, pseudobacteremia, and therapy of patients. J Clin Microb. 1998;36:1923-6.

12. Iwantscheff A, Kuhnen E, Brandis H. Species distribution of coagulase-negative staphylococci isolated from clinical sources. Zentralbl Bakteriol Mikrobiol Hyg [A]. 1985;260:4150.

13. Pal N, Ayyagari A. Species identification and methicillin resistance of coagulase negative staphylococci from clinical specimens. Indian J Med Res. 1989;89:300-5.

14. Refsahl K, Andersen BM. Clinically significant coagulasenegative staphylococci: identification and resistance patterns. J Hosp Infect. 1992;22:19-31.

15. Gill VJ, Selepak ST, William EC. Species identification and antibiotic susceptibilities of coagulase-negative staphylococci isolated from clinical specimens. J Clin Microbiol. 1983;18:1314-9.

16. Sewell CM, Clarridge JE, Young EJ, Guthrie RK. Clinical significance of coagulase negative staphylococci. J Clin Microbiol. 1982;16:236-9.
17. Smith IM, Beals PD, Kingsbury KR, Hasenclever HF. Observations on staphylococcus albus septicemia in mice and men. Arch Intern Med. 1958;102:375-88.

18. Stillman RI, Wenzel RP, Donowitz LG. Emergence of coagulase-negative staphylococci as major nosocomial bloodstream pathogens. Infect Control. 1987;8:108-12.

19. Spencer RC. Predominant pathogens found in the European prevalence of infection in intensive care study. Eur J Clin Microbiol Infect Dis. 1996;15:281-5.

20. Richardson JF, Marples RR. Changing resistance to antimicrobial drugs, and resistance typing in clinically significant strains of Staphylococcus epidermidis. J Med Microbiol. 1982;15:475-84.

21. Deepak S, Samant SA, Urhekar AD. Study of coagulase positive and negative staphylococci in clinical samples. Indian J Med Sci, 1999;53:425-8.

22. Ponce de Leon S, Wenzel RP. Hospital acquired bloodstream infections with Staphylococcus epidermidis. Review of 100 cases. Am J Med. 1984;77:639-44.

23. Foleno BD, Lafredo SC, Fu KP. In vitro activity of levofloxacin, ofloxacin and other quinolones against coagulase negative staphylococci. Chemotherapy. 1993;39:120-3. 